\title{
Two journeys: The Machine with 5 Hearts; Duchamp and Travel
}

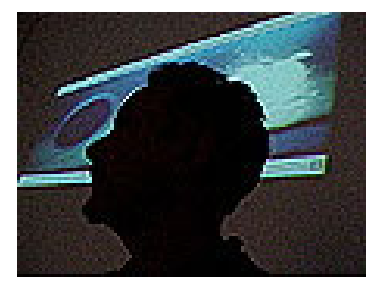

Kyeran Lyons

k.lyons@1649.ndo.co.uk

\begin{abstract}
The 'posthuman' condition described by Katherine Hayles (1999), looks to the definitions of Hans Moravec and beyond these to the pioneering thinking of Alan Turing. I have begun to make a detailed study of an event that seems to predict these definitions of hybrid forms when Marcel Duchamp wrote the notes for his automobile journey in 1912, called The Jura-Paris Road. The note appears in his Notes for the Green Box (1934) and in the later group of Notes, published after his death by Pierre Matisse (1980). In his description of this journey, Duchamp and his fellow travellers seem to network with one another while merging their sensibilities with the electrical processes and mechanics of the automobile. The characters that Duchamp describes in this note make them early precursors of the cyborg condition and part of this presentation will be devoted to an examination of this relationship. Also, Duchamp makes suggestions about the spatial distances and temporal register of the journey. This synthesis between the travellers, their car and the physical features of the road, (its length, time and its surface condition) suggests also the strange geometries that he began to investigate with his Three Standard Stoppages of 1913 . I will also be looking at a separate journey that Duchamp took in the spring of 1912 that seems to predict this interest in dimensional and topological thinking.
\end{abstract}

My source for this text comes from Francis Caumont \& Jennifer Gough Cooper's Ephemerides (1993) and is listed in the section under March 17th 1912.

On that day Marcel Duchamp delivered his painting The Nude Descending a Staircase. No.2. to the Spring exhibition at the Salon des Indépendants in Paris. In order to do this he went by rowing boat. He would have gone from his house at the Paris periphery to the Quai d'Orsay at its centre. This meant rowing against the current. A perverse undertaking on a river that was flowing in a direction that was contrary to his direction of travel. He could have gone there by road, very easily.

The presentation in Barcelona on the 12th July dealt with the possible reasons behind this improbable journey and I attempted to link it thematically with a second journey that he took in 1912 with Picabia and Apollinaire. This second journey was designated The Jura-Paris Road and it appears in Note form in the Green Box (1934) as well as the edition of Notes, published by Duchamp's son in law, Paul Matisse in 1980. My presentation was illustrated with an accompanying Director movie that ran simultaneously, from which I have included some images here.

I prefaced my discussion by showing a new piece of work called simply 144 Number Plates which is currently showing in an exhibition called 'A470' at Chapter Arts Centre in Cardiff, South Wales. A version of this work can be seen online at http://www.onnos.com/kieran/A470.html 
This work also deals with a car journey and following the spirit of Duchamp's Notes, I tried to make a work that treated the journey as a mesmerising experience.

Accordingly the individual details of landscape and topography are subsumed into a generic formula of automobile journeys in 2001. The details of this formula are the view through the windshield that consists of the black Registration Disc on the left and the lights of the oncoming traffic on the right. Between them is the road that is obscured by the endless rain.

In October 1912, Duchamp and his friends arrived at their destination in the Jura in a terrible and frightening rainstorm.
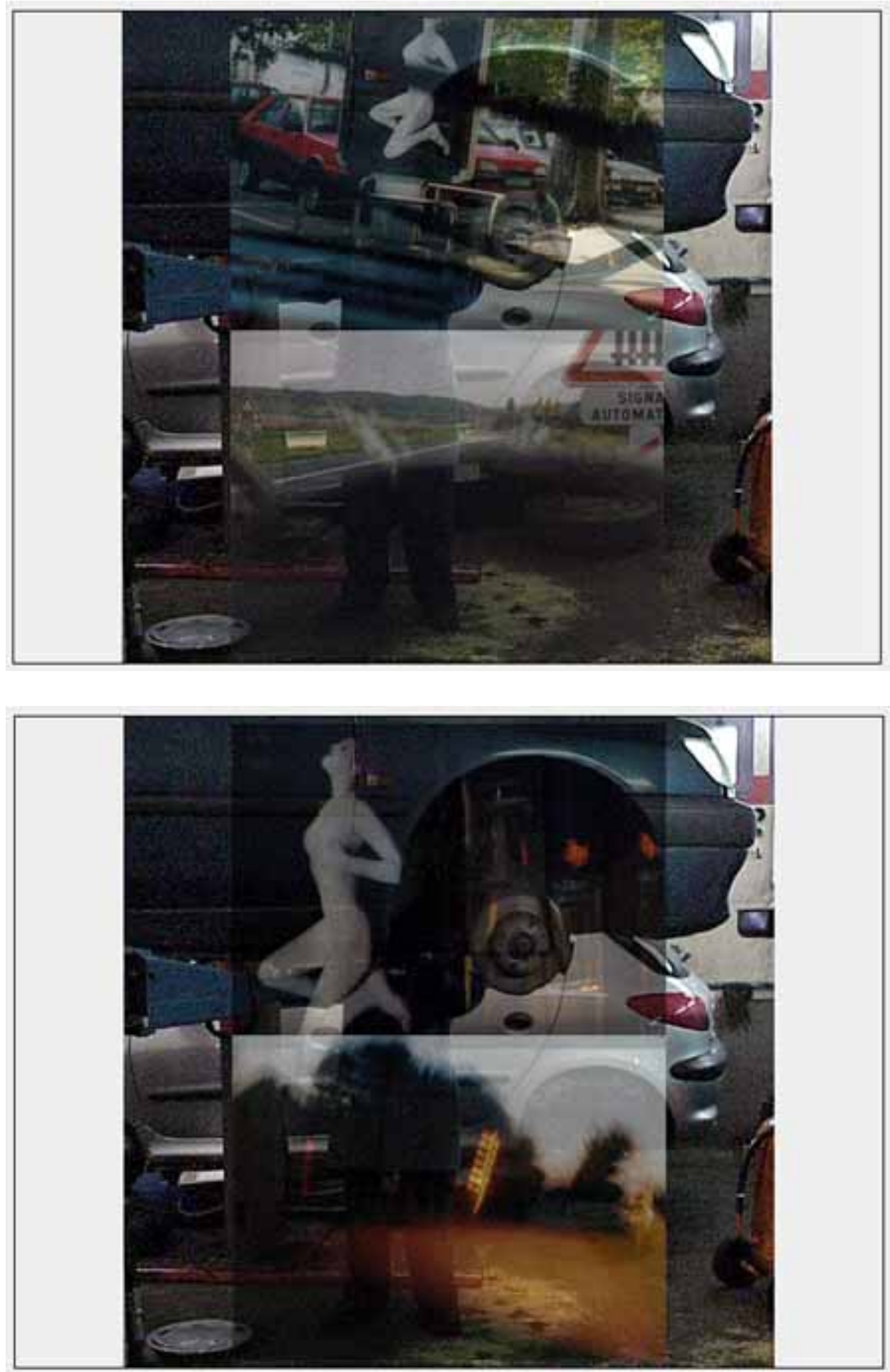

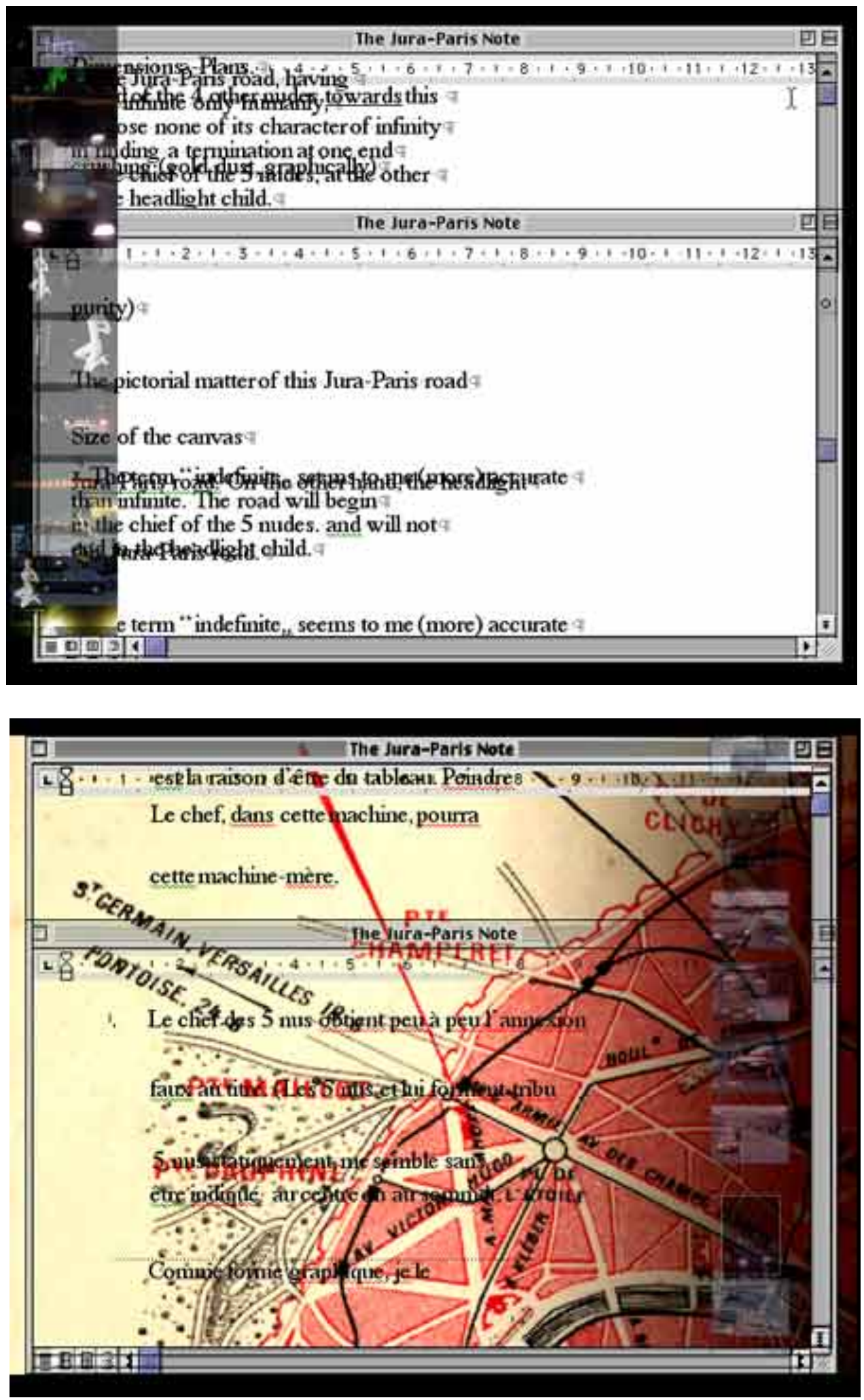

[Published on: december 2001]

@ Kyeran Lyons, 2001

\section{Recommended citation:}

LYONS, Kyeran (2002). "Two journeys: The Machine with 5 Hearts; Duchamp and Travel. Artnodes, issue 1 [article online].

DOI: http://dx.doi.org/10.7238/a.v0i1.669 